\title{
TEOREMA PEMBAGIAN PADA RING POLINOMIAL $R[X]$
}

\author{
ORIEN LUISA, YANITA, NOVA NOLIZA BAKAR \\ Program Studi S1 Matematika, \\ Fakultas Matematika dan Ilmu Pengetahuan Alam, Universitas Andalas, \\ Kampus UNAND Limau Manis Padang, Indonesia. \\ email : orienluisa12@gmail.com
}

Diterima 9 Maret 2019 Direvisi 7 April 2019 Dipublikasikan 7 Mei 2019

\begin{abstract}
Abstrak. Teorema pembagian terdapat pada himpunan bilangan bulat $\mathbb{Z}$ dan dapat diperluas pada ring polinomial $R[X]$. Dengan $R$ yang suatu ring komutatif, $R[X]=$ $\left\{a_{n} X^{n}+a_{n-1} X^{n-1}+\cdots+a_{1} X+a_{0} \mid a_{i} \in R, n\right.$ adalah bilangan bulat non-negatif $\}$ merupakan himpunan yang memuat semua polinomial atas $R$ dalam variabel tak tentu $X$. Pada penelitian ini dikaji Teorema pembagian pada ring polinomial $R[X]$ dan bagaimana suatu polinomial pada ring polinomial $R[X]$ terevaluasi di $r \in R$.
\end{abstract}

Kata Kunci: Ring, Polinomial, Ring Polinomial $R[X]$, Evaluasi, Homomorfisma

\section{Pendahuluan}

Pada operasi pembagian himpunan bilangan bulat $\mathbb{Z}$ terdapat suatu Teorema Pembagian (Division Theorem) [3]. Teorema ini terkait dengan suatu bilangan bulat yang jika dibagi dengan bilangan bulat lain akan memiliki hasil bagi dan sisa, sedemikian sehingga $a=b q+r$ dengan $0 \leqslant r<|b|$ dimana $a, b \in \mathbb{Z}$. Pada teorema ini, $q$ adalah hasil bagi bilangan bulat $a$ oleh bilangan bulat $b$ dan $r$ adalah sisa dari pembagian tersebut, nilai $q$ dan $r$ tunggal di $\mathbb{Z}$.

Ring merupakan suatu himpunan tak kosong dengan dua operasi biner yaitu penjumlahan dan perkalian yang memenuhi beberapa aksioma. Ring dinotasikan dengan $R$. Suatu ring $R$ dikatakan ring komutatif jika $a \cdot b=b \cdot a$, untuk setiap $a$, $b \in R[8]$.

Suatu fungsi $f(x)$ disebut polinomial apabila $f(x)$ dapat ditulis sebagai $f(x)=$ $a_{0}+a_{1} x+a_{2} x^{2}+\cdots+a_{n} x^{n}$ dimana $n$ suatu bilangan bulat non-negatif dan $a_{0}, a_{1}, a_{2}, \cdots, a_{n}$ adalah koefisien dari $f(x)$. Koefisien $a_{0}, a_{1}, a_{2}, \cdots, a_{n}$ merupakan elemen-elemen dari suatu himpunan.

Jika $R$ suatu ring komutatif, maka ring polinomial $R[X]$ merupakan himpunan yang memuat semua polinomial dalam variabel tak tentu $X$, yang koefisien-koefisien untuk setiap polinomialnya berada di $R$.

Oleh karena itu, pada penelitian ini akan dijelaskan bagimana Teorema Pembagian itu juga berlaku pada ring polinomial $R[X]$ dan bagaimana suatu polinomial pada ring polinomial $R[X]$ tersebut terevaluasi di $r \in R$. 


\section{Landasan Teori}

\subsection{Pembagi Persekutuan Terbesar (Greatest Common Divisor)}

Definisi 2.1. [4] Misalkan $a, b \in \mathbb{Z}$, dengan $a \neq 0$, dikatakan a membagi habis $b$ jika terdapat suatu elemen $c \in \mathbb{Z}$, sedemikian sehingga $b=a c$. Simbol :

(1) Jika a membagi habis b, maka ditulis dengan $a \mid b$.

(2) Jika a tidak membagi habis b, maka ditulis dengan $a \nmid b$.

Definisi 2.2. [4] Misalkan $a, b \in \mathbb{Z} \backslash\{0\}$, terdapat $d \in \mathbb{Z}^{+}$yang tunggal, $d$ dikatakan pembagi persekutuan terbesar(greatest common divisor) dari a dan $b$ jika memenuhi sifat berikut :

(1) $d \mid$ a dan $d \mid b$.

(2) Jika $c \mid$ a dan $c \mid$ b, maka $c \mid d$.

Jika d pembagi persekutuan terbesar dari a dan b, maka disimbolkan dengan ppb(a,b) atau $\operatorname{gcd}(a, b)$.

\subsection{Fungsi}

Definisi 2.3. [1] Misalkan $A$ dan $B$ adalah dua himpunan tak kosong, $f$ dikatakan suatu fungsi dari $A$ ke $B$ jika setiap unsur di $A$ dipetakan secara tunggal ke suatu unsur di $B$, ditulis $f: A \rightarrow B$. Apabila $f$ memetakan suatu $x \in A$ ke suatu $y \in B$ maka $y$ disebut peta dari $x$, ditulis dengan $f: x \mapsto y$, sedangkan $x$ disebut prapeta dari y. Himpunan A dinamakan daerah asal (domain) dari fungsi $f$ dan himpunan $B$ dinamakan daerah kawan (kodomain) dari fungsi f tersebut.

Definisi 2.4. [1] Misalkan $f: A \rightarrow B$ suatu fungsi dari $A$ ke $B$.

(1) Injektif (Satu-satu)

Fungsi $f$ dikatakan injektif (satu-satu) jika untuk setiap $x_{1}$ dan $x_{2}$ di A dengan $x_{1} \neq x_{2}$ maka $f\left(x_{1}\right) \neq f\left(x_{2}\right)$.

(2) Surjektif (Pada)

Fungsi $f$ dikatakan surjektif (pada) jika $f(A)=B$, yang berarti daerah hasil $R(f)=B$.

(3) Bijektif (korespondensi satu-satu)

Fungsi $f$ dikatakan bijektif jika $f$ injektif dan surjektif.

\subsection{Well-Ordering Principle (Prinsip Terurut dengan Baik)}

Definisi 2.5. [2] Jika $S$ adalah himpunan bilangan bulat non-negatif dan $S$ tak kosong, maka $S$ memuat elemen terkecil, yaitu terdapat bilangan bulat a $\in S$ sedemikian sehingga $a \leqslant b$ untuk setiap $b \in S$. 


\subsection{Ring}

Definisi 2.6. [8] Himpunan tak kosong $R$ dikatakan suatu ring jika pada $R$ terdapat dua operasi yang dinyatakan dengan " + "dan "." , sedemikian sehingga untuk setiap $a, b, c \in R$ berlaku :

(1) $a+b \in R$,

(2) $a+b=b+a$,

(3) $(a+b)+c=a+(b+c)$,

(4) Terdapat sebuah 0 di $R$ sehingga $a+0=a$ (untuk setiap $a \in R$ ),

(5) Terdapat sebuah $-a \in R$ sehingga $a+(-a)=0$,

(6) $a \cdot b \in R$,

(7) $(a \cdot b) \cdot c=a \cdot(b \cdot c)$,

(8) $a \cdot(b+c)=a \cdot b+a \cdot c$ dan $(a+b) \cdot c=a \cdot c+b \cdot c$.

Definisi 2.7. [8] Suatu ring $R$ dikatakan ring dengan unsur satuan, jika terdapat $1 \in R$ sedemikian sehingga $a \cdot 1=1 \cdot a=a, \forall a \in R$.

Definisi 2.8. [8] Suatu ring $R$ dikatakan ring komutatif jika $a \cdot b=b \cdot a, \forall a, b \in R$.

Definisi 2.9. [8] Jika $R$ suatu ring komutatif, maka $a \neq 0 \in R$ dikatakan pembagi nol, jika terdapat $b \in R$ dengan $b \neq 0$ sedemikian sehingga $a b=0$.

Definisi 2.10. [8] Suatu ring komutatif $R$ dikatakan daerah integral, jika $R$ tidak mempunyai pembagi nol.

Definisi 2.11. [9] Misalkan $R$ suatu ring, $S \subseteq R$, dan $S \neq \emptyset$. $S$ disebut subring dari $R$ jika $S$ dengan operasi biner penjumlahan dan perkalian yang sama dengan $R$ juga merupakan ring.

Definisi 2.12. [8] Pemetaan $\phi$ dari ring $R$ ke ring $\boldsymbol{R}$ dikatakan suatu homomorfisma ring jika :

(1) $\phi(a+b)=\phi(a)+\phi(b)$

(2) $\phi(a . b)=\phi(a) \cdot \phi(b)$

untuk setiap $a, b \in R$.

\subsection{Ring Polinomial}

Definisi 2.13. [10] Suatu polinomial dalam variabel tak tentu $x$ adalah jumlah hingga dari monomial dengan derajat berbeda. Polinomial dalam variabel tak tentu $x$ dinotasikan dengan $f(x), g(x), h(x)$, dan sebagainya. Suatu fungsi $f(x)$ disebut polinomial apabila $f(x)$ dapat ditulis sebagai

$$
f(x)=a_{0}+a_{1} x+a_{2} x^{2}+\cdots+a_{n} x^{n}
$$

dimana $n$ suatu bilangan bulat non-negatif dan $a_{0}, a_{1}, a_{2}, \cdots, a_{n}$ adalah koefisien dari $f(x)$. Koefisien $a_{0}, a_{1}, a_{2}, \cdots, a_{n}$ merupakan elemen-elemen dari suatu himpunan. Suku $a_{0}$ disebut suku konstanta dari polinomial. Suku $a_{n} x^{n}\left(a_{n} \neq 0\right)$ disebut 
suku utama, koefisiennya disebut koefisien utama dan derajatnya disebut derajat dari polinomial. Derajat dari $f(x)$ dinotasikan dengan deg $(f(x))$.

Definisi 2.14. [6] Misal $R$ suatu ring komutatif.

$R[X]=\left\{a_{n} X^{n}+a_{n-1} X^{n-1}+\cdots+a_{1} X+a_{0} \mid a_{i} \in R\right.$, nadalahbilanganbulatnon-negatif $\}$.

merupakan himpunan yang memuat semua polinomial atas $R$ dalam variabel tak tentu X. Dua elemen

dan

$$
a_{n} X^{n}+a_{n-1} X^{n-1}+\cdots+a_{1} X+a_{0}
$$

$$
b_{m} X^{m}+b_{m-1} X^{m-1}+\cdots+b_{1} X+b_{0}
$$

di $R[X]$ dianggap sama jika dan hanya jika $a_{i}=b_{i}$ untuk semua bilangan bulat non-negatif $i$.

Definisi 2.15. [6] Penjumlahan dan perkalian pada $R[X]$

Misal $R$ suatu ring komutatif dan misalkan $f[X], g[X] \in R[X]$ dengan

$$
\begin{aligned}
& f(X)=a_{n} X^{n}+a_{n-1} X^{n-1}+\cdots+a_{1} X+a_{0}, \\
& g(X)=b_{m} X^{m}+b_{m-1} X^{m-1}+\cdots+b_{1} X+b_{0} .
\end{aligned}
$$

Maka

$$
\begin{aligned}
f(X)+g(X)= & \left(a_{s}+b_{s}\right) X^{s}+\left(a_{s-1}+b_{s-1}\right) X^{s-1}+\cdots+\left(a_{1}+b_{1}\right) X+a_{0}+b_{0}, \\
& s=\max \{m, n\} \\
f(X) g(X)= & c_{m+n} X^{m+n}+c_{m+n-1} X^{m+n-1}+\cdots+c_{1} X+c_{0}, \\
& c_{k}=a_{k} b_{0}+a_{k-1} b_{1}+\cdots+a_{1} b_{k-1}+a_{0} b_{k}, k=0, \cdots, m+n .
\end{aligned}
$$

Proposisi 2.16. [7] Untuk setiap $f(X), g(X) \neq \boldsymbol{O} \in R[X]$ berlaku :

(1) Jika $\operatorname{deg}(f(X)) \neq \operatorname{deg}(g(X)), \quad$ maka $\operatorname{deg}(f(X)+g(X))=$ $\max (\operatorname{deg}(f(X)), \operatorname{deg}(g(X)))$.

(2) Jika $R$ tidak mempunyai pembagi nol, maka $\operatorname{deg}(f(X) g(X))=\operatorname{deg}(f(X))+$ $\operatorname{deg}(g(X))$.

\subsection{Teorema Pembagian pada $\mathbb{Z}$}

Teorema 2.17. [3] Untuk sebarang $a, b \in \mathbb{Z}$, dengan $b \neq 0$, terdapat $q \in \mathbb{Z}$ dan $r$ $\in \mathbb{Z}$ yang tunggal, sedemikian sehingga

$$
a=b q+r, \text { dengan } 0 \leq r<|b| \text {. }
$$

Salah satu penggunaan dari Teorema Pembagian pada himpunan bilangan bulat $\mathbb{Z}$ adalah untuk menentukan gcd (greatest common divisor), yaitu pada saat $r=$ 0 atau dengan kata lain $a$ habis dibagi oleh $b$ karena sisa pembagian adalah 0 . Selanjutnya, teorema pembagian ini diperluas pada ring polinomial $R[X]$. 


\section{Pembahasan}

\subsection{Teorema Pembagian pada Ring Polinomial R[X]}

Teorema 3.1. [5] Himpunan $R[X]$ dari semua polinomial dalam variabel tak tentu $X$ dengan koefisiennya dalam suatu ring $R$, membentuk ring terhadap operasi penjumlahan dan perkalian polinomial. Jika $R$ komutatif, maka $R[X]$ juga komutatif dan jika $R$ mempunyai unsur satuan 1, maka 1 juga unsur satuan untuk $R[X]$.

Teorema 3.2. [3] Untuk sebarang $f(X)$ dan $g(X) \in R[X]$, dengan $g(X) \neq \boldsymbol{0}$, terdapat $q(X)$ dan $r(X) \in R[X]$ yang tunggal, sedemikian sehingga

$$
f(X)=g(X) q(X)+r(X)
$$

dengan $r(X)=\mathbf{O}$ atau $\operatorname{deg}(r(X))<\operatorname{deg}(g(X))$.

\subsection{Evaluasi}

Definisi 3.3. [7] Misalkan $A \in R[X]$ dengan $A=a_{n} X^{n}+a_{n-1} X^{n-1}+\cdots+a_{1} X+$ $a_{0}$. Untuk setiap $A \in R[X], A$ dikatakan terevaluasi di $r \in R$ jika

$$
A(r)=a_{n} r^{n}+a_{n-1} r^{n-1}+\cdots+a_{1} r+a_{0} \in R .
$$

Proposisi 3.4. [7] Jika $R$ komutatif, maka evaluasi di $r \in R$ adalah suatu homomorfisma dari $R[X]$ ke $R$. Lebih umumnya, jika $R$ adalah suatu subring dari $S$ dan $s \in S$ komutatif dengan setiap elemen di $R$, maka evaluasi di $s$ adalah suatu homomorfisma dari $R[X] \subseteq S[X]$ ke $S$.

\section{Kesimpulan}

Berikut merupakan kesimpulan berdasarkan hasil pembahasan :

(1) Jika pada himpunan bilangan bulat $\mathbb{Z}$ berlaku Teorema Pembagian sebagai berikut: untuk sebarang $a, b \in \mathbb{Z}$, dengan $b \neq 0$, terdapat tunggal $q \in \mathbb{Z}$ dan $r \in \mathbb{Z}$, sedemikian sehingga $a=b q+r$ dengan $0 \leqslant r<|b|$; maka pada ring polinomial $R[X]$ juga berlaku Teorema Pembagian yang analog dengan Teorema Pembagian pada himpunan bilangan bulat $\mathbb{Z}$, sehingga dapat diperoleh sebagai berikut : untuk sebarang $f(X)$ dan $g(X) \in R[X]$, dengan $g(X) \neq \mathbf{0}$, terdapat tunggal $q(X)$ dan $r(X) \in R[X]$, sedemikian sehingga $f(X)=g(X) q(X)+r(X)$ dengan $r(X)=\mathbf{0}$ atau $\operatorname{deg}(r(X))<\operatorname{deg}(g(X))$.

(2) Misalkan $A \in R[X]$ dengan $A=a_{0}+a_{1} X+\cdots+a_{n-1} X^{n-1}+a_{n} X^{n}$. Polinomial $A$ dapat dievaluasi di $r \in R$ jika $A \in R[X]$ dan $r \in R$ sedemikian sehingga

$$
A(r)=a_{0}+a_{1} r+\cdots+a_{n-1} r^{n-1}+a_{n} r^{n} \in R .
$$

(3) Jika $R$ komutatif, maka evaluasi di $r \in R$ adalah suatu homomorfisma dari $R[X]$ ke $R$. 
254 Orien Luisa Hura dkk

\section{Ucapan Terima kasih}

Penulis mengucapkan terima kasih kepada bapak Dr. Admi Nazra, Bapak Dr. Ahmad Iqbal Baqi dan Bapak Dr. Mahdhivan Syafwan selaku penguji sehingga makalah ini dapat diselesaikan dengan baik.

\section{Daftar Pustaka}

[1] Bartle, R.G. and Sherbert, D.R. 2000. Introduce To Real Analysis $3^{\text {rd }}$ Edition. John Wiley and Sons, USA

[2] Burton, D.M. 1976. Elementary Number Theory. Allyn and Bacon, USA

[3] Conrad, K. 1973. The Division Theorem in $\mathbb{Z}$ and $R[\mathrm{~T}]$. Amer Math, USA

[4] Dummit, D.S. and Foote, R.M. 1991. Abstract Algebra. Prentice-Hall, USA

[5] Fraleigh, J.B. 2003. A First Course In Abstract Algebra $7^{\text {th }}$ Edition. AddisonWesley, Boston

[6] Gallian, J.A. 2006. Contemporary Abstract Algebra $7^{\text {th }}$ Edition. Brooks/Cole, USA

[7] Grillet, P.A. 2007. Abstract Algebra $2^{\text {nd }}$ Edition. Springer, USA

[8] Herstein, I.N. 1975. Topics In Algebra $2^{\text {nd }}$ Edition. Wiley, New York

[9] Herstein, I.N. 1996. Abstract Algebra $3^{\text {rd }}$ Edition. Prentice-Hall, USA

[10] Leung, K.T. and Mok, I.A.C. and Suen, S.N. 1992. Polynomials And Equations. Hong Kong University Press, Hong Kong 